\title{
The Opportunities and Challenges of Digital Libraries in the Big Data Era
}

\author{
Sun Guimei \\ Xi'an Fanyi University Library, Shaanxi, China, 710118
}

Keywords: Big data era; Digital library; Opportunities and challenges

Abstract: With the development of network resources, digital libraries will face great challenges. Digital libraries should create the big data model and expand the scope of resources. At the level of technology application, clustering technology should be gradually strengthened and improved. The application of data analysis in the system will quickly improve the retrieval technology. At the level of service, digital library service mode will be more automatic, active and personalized. Digital libraries should break the shackles of traditional rules and regulations. It is believed that digital libraries will concentrate resources and upgrade service concepts.

\section{Introduction}

In the big data era, the construction speed of network academic resources has been improved and gradually replaced the trend of traditional libraries. Digital libraries should not only have big data thinking, but also expand the scope of resources. We must improve the integration, depth and breadth of resources. Digital library service mode transforms passive and waiting service mode into automatic push personalized service. At present, some foreign related research institutes have studied the construction of digital libraries in the big data era. They have successfully applied embedded technology into the digital library system and realized the combination of digital library and digital technology. With the increasing demand for data, the function of digital library has become more and more important. Facing the challenge of big academic resources data, we must perfect digital library. We must strengthen the cultivation of personnel quality and then translate the service mode. The new service concept will accelerate the development of digital library.

\section{The necessity of building digital library in China}

\subsection{The big data impact}

With the rapid development of science and technology, more and more attention has been paid to the construction of academic resources. Digital library is under increasing pressure, so digital library staff must see opportunities from challenges. Digital library staff must fully consider the digital library planning and realize the organic combination of various resources. Only by fully exploiting the potential value, can we realize the effective and efficient utilization of resources. 


\subsection{The convenience of data resources}

Compared with traditional libraries, digital libraries are more convenient in the utilization of data resources. In the traditional library, all the data are stored in the form of text, which is inconvenient to query. The data may be just a bunch of meaningless Numbers. However, it is different in digital libraries. Digital library can make use of the digital technology in the big data era, which can make the text data stored in the traditional library play its value. Before the wide application of science and technology, library is in the position of knowledge service center in the knowledge society. But with the widespread application of science and technology, library is not only a document center, but also a data center. Big data can not only improve the productivity and competitiveness of enterprises, but also promote Chinese economic development.

\section{The challenges of digital libraries in the big data era}

\subsection{The collection function of library is challenged}

With the tide of digitization sweeping the world, the digitization of library information resources is developing rapidly. According to the California University, the amount of new information in the world is doubling every three years, and about 90 percent is stored digitally in some kind of computer device. In 1998 only 30\% of SCI's cited journals were published online, up from 75\% in 2002. Users also prefer to access these resources online. Under the background of digitization, the function of library collection has been challenged unprecedentedly.

\subsection{The organization of library information service is challenged}

With the development of computer and communication technology, human beings have entered the network era. The rapid development of Internet makes information proliferate. More and more individuals and academic groups publish their research results and papers on the Internet. Together with a large number of online databases and electronic journals, they have formed a huge multidisciplinary, multi-literary and exceptionally dispersed online literature. The growth of online literature is also accelerating and exploding. If the traditional library uses the original way, it will not be suitable for the new era needs. Which is a dilemma facing librarians today.

\section{The opportunities of digital libraries in the big data era}

\subsection{The principles of digital library information resources construction}

\subsubsection{Integrity principle}

In the digital environment, library collaboration becomes necessary. Because the current information resources are interrelated, the library must set up an effective information guarantee system. Only by strengthening the communication and interaction between libraries, can we better serve users.

\subsubsection{Systemic principle}

Under the digital environment, the library faces a sea of information resources. It is necessary to ensure that the information resources collected and stored are reliable, systematic and complete. We must establish the authoritative image of digital library information resources in readers' mind. Only in this way can more users be attracted to the library's digital resources. 


\subsubsection{Standardization principle}

Digital libraries must emphasize the principle of standardization. Standardization of information resources ensures the convenience of query services. Standardization is the foundation of digital library, which directly affects the quality of resource library and query service. The content of standardization mainly includes the standardization of data format, description and indexing language. Data formats must be standardized. Only in this way can data be exchanged between different computer systems. The standardization of description and indexing language can realize the effective communication between user and system.

\subsection{Positioning of digital library}

\subsubsection{Break away from the traditional library resource frame}

Big data brings us to a vast data space. Digital library is facing not only books, periodicals and other literature information, but also a variety of information on the network. The various needs for digital libraries have led to great changes in data collection, processing, organization and service. We must construct new digital library resource frame. Digital library is not only limited to the literature resources, but also should put the whole network resources into the framework system. Information acquisition requires traditional ordering method and automatic acquisition technology of network information. Which requires a tighter framework for organizing information.

\subsubsection{Establish a comprehensive service concept}

The basic service of traditional library is document service, and the forms are mostly waiting and passive services. The service resources of digital library greatly enrich the library resources. The form of service changed from passive service to self-service. However, the service concept of digital library needs to be further improved, and a comprehensive service concept should be established. First, serve the whole society. The copyrighted digital library content established by universities and research institutes should also serve the whole society. Second, full resource services. Digital libraries should provide services of various information resources, such as literature information, database information, network information, video information, analysis information, policies and regulations, government information, etc. Third, expand the service mode and communication form. Digital libraries should not only provide users with self-service and brief information, but also provide push service and personalized service. After the establishment of virtual reference platform, digital library should not only provide services for fixed network, but also mobile network.

\subsubsection{Positioning of digital library librarians}

The big data era also puts forward higher requirements for digital library librarians. Every librarian should have the ability to understand and analyze data. Librarians who have a certain understanding of big data technology should learn to use the key technologies of big data in digital libraries. They must be proficient in various data analysis tools and software.

\subsection{Establish digital library information platform}

In the era of big data, information is the most valuable product. Multifarious information will be the biggest problem faced by digital libraries in the big data era. This information is important for math libraries. Information processing should not only make full use of traditional information 
processing functions, but also effectively apply information technology processing. At present, most of the library platform construction progress is slow, and the relationship between the platforms are not close. Although there are a large number of platforms, most of them are small ones and operate independently, which will be causing unnecessary waste of resources. Information platform is a platform for centralized processing of all aspects.

\section{Conclusions}

With the coming of digital era, the transition from traditional library to digital library is an inevitable trend. Libraries have no choice but to adapt themselves to the changing times. We must seize the opportunities, meet the challenges and lay a solid foundation for our future. Under the background of big data, the development of digital library needs to change the traditional service mode. We must break away from the frame of traditional library resources and establish a comprehensive service concept. The reform of traditional library is an integral part of information revolution and also a systematic project. The success or failure has a great impact on the development of the whole social information, so it must be paid enough attention by the library staff. Through the library reform, the social information service system will be more perfect. Although digital library faces challenges such as open access environment, knowledge economy and so on. Digital library is adhering to the "people-oriented", "reader first" belief, we will be able to challenge into opportunities.

\section{References}

[1] Huwe T K. Building digital libraries: big data and the library: a natural fit [J]. Computers in Libraries, 2014(2):17-18.

[2] Renaud J, Britton S, Wang D. Mining library and university data to understand library use patterns [J]. The Electronic Library, 2015, 33(3):355-372.

[3] Li Baiyang, Zhang Xinyuan. Preliminary study of the big data mechanism in digital library construction [J]. Information Science,2013(11):26-29.

[4] Chen Mang, Zhou Liqing. Research about library mobile service innovation in big data era [J]. Library and Information, 2014(1):117-121. 